Artigo Original

\title{
Estudo comparativo de variáveis bioperacionais entre atletas de desportos de diferentes demandas
}

\author{
Nilo Terra Arêas Neto ${ }^{1}$ \\ Anderson Pontes Morales ${ }^{1}$ \\ Luciano Honório Dias ${ }^{2}$ \\ Marcos Wellington Sales de Almeida ${ }^{1}$ \\ Vernon Furtado da Silva ${ }^{3}$ \\ ${ }^{1}$ Mestre em Ciência da Motricidade Humana, LANPEM da Universidade Castelo Branco \\ $U C B$, Rio de Janeiro, RJ, Brasil \\ ${ }^{2}$ Mestrando em Ciência da Motricidade Humana, Universidade Castelo Branco UCB, Rio \\ de Janeiro, RJ, Brasil \\ ${ }^{3}(P h D)$ Programa Stricto Sensu em Motricidade Humana LANPEM da Universidade \\ Castelo Branco UCB, Rio de Janeiro, RJ, Brasil
}

\begin{abstract}
Resumo: Este estudo teve por função mensurar e comparar os escores de atletas de desportos de diferentes demandas, em variáveis bioperacionais. Para tanto, selecionou-se trinta $(\mathrm{N}=30)$ atletas do gênero masculino, com idade entre 13 e 16 anos, sendo 15 atletas de basquetebol e 15 velocistas do atletismo. As variáveis coordenação geral, percepção cinestésica e tempo de reação motriz foram mensuradas por meio de testes aplicados na seguinte ordem, teste de Burpee, teste de Salto Percepção Cinestésica e teste de Tempo de Reação Motriz. Os dados obtidos foram tratados e analisados no programa SSPS 10. Na versão descritiva utilizou-se os escores mínimos e máximos, as médias e desviospadrão, na estatística inferêncial, o teste "t" student. O teste da hipótese do estudo teve como referência o valor de alfa $p \leq 0,05$. Os resultados apontaram o tempo de reação dos atletas de basquetebol como variável que obteve significância estatística na comparação entre grupos.
\end{abstract}

Palavras-chave: Basquetebol. Atletismo. Atletas.

\section{Study comparative of variables bioperational among athletes of sports of different demands}

\begin{abstract}
This study had the task of comparing and measuring the scores of sports athletes of different demands raised here, the basketball and athletics, in varying bioperacionais. Thirty $(\mathrm{N}=30)$ athletes of the masculine gender were selected, with age between 13 and 16 years, 15 basketball athletes and 15 athletes velocitys. The variables overall coordination, cinestesic perception and reaction time, were measured by means of tests that were applied in the following order, Burpee test; Jump Cinestesic Perception and test the reaction time. Data from the testing procedures were processed and analyzed in the program SSPS 10. In the version used to the descriptive means and standard deviations for the two times of testing. In statistical inference used to test the " $t$ " student. The test of the hypothesis of the study was to reference the value of alpha $p \leq 0.05$. The basketball athletes were pointed to have a better score in this variable. The results pointed to the reaction time of driving as the variable that has obtained statistical significance between the groups.
\end{abstract}

Key Words: Basketball. Athletics. athletes.

\section{Introdução}

A motricidade humana é subservida por uma série de mecanismos e processos neurais, que em decorrência de seus centros estruturadores e controladores organizam todas as funções de motricidades inerentes à vida como um todo.

Ao se estudar tais mecanismos cabem uma série de divisões neurais integradas em dois sistemas específicos, definidos por $\mathrm{Da}$ Silva (2002b), como sistemas bioestruturais e bioperacionais do movimento humano. Para a divisão bioestrutural do sistema nervoso, entende-se que são as que possuem dependência e estão mais diretamente relacionadas, às capacidades quantitativas do organismo neuromuscular. O termo quantitativo é referido aqui principalmente para definir a capacidade do sistema nervoso para: 1) gerar impulsos nervosos, 2) recrutar neurônios, 3) atender as demandas fisiológicas do movimento, 4) atender as demandas emocionais implícitas 
em eventos de treinamento e prática desportiva, 5) conduzir impulsos nervosos, 6) proceder a processos sinápticos de uma forma em geral e 7) proceder às gestões funcionais, estrutural e mecânica das articulações e dos músculos como um todo. Ao analisar as características do compêndio bioestrutural, pode-se afirmar que quanto maior for à competência do sistema nervoso em atuar sobre cada uma destas variantes, maior será a competência estrutural da mesma. Ou seja, a função de recrutamento neural do sistema nervoso estaria quantitativamente melhor (ou maior), quando este passasse a recrutar, em um mesmo tipo de evento, uma maior quantidade de neurônios para realizá-lo do que antes recrutava.

A divisão bioperacional, corresponde à capacidade do Sistema Nervoso para estruturar, implementar e regular (controlar), resultantes físicas da produção bioestrutural, relativamente e eficientemente às demandas ambientais. Suas funções estão implícitas, no processamento mental humano, ocasião em que, o cérebro e a mente, se conjugam em elaboração dos pensamentos. Seria a capacidade do indivíduo de processar, em percepção, abstração e lógica (DA SILVA, 2002a).

Pensando-se em termos de habilidades motoras, é natural o entendimento de que níveis destas competências devam estar associados à competência de um indivíduo e à demanda da atividade, na qual estas são verificadas. As habilidades motoras básicas são consideradas à base da competência motora, a qual pode ser explicada como a capacidade do indivíduo em resolver problemas, enfrentar as situações, se organizar, planejar, transformar o meio, sentindose competente, ao ter conhecimento dos processos e atitudes e, adaptando-os a situação presente.

A aquisição das habilidades motoras básicas é pré-requisito para a aquisição de habilidades mais complexas. Não seria incorreto dizer que as habilidades motoras básicas são auxiliares na conquista da independência da criança, visto que, a percepção progressiva do ato motriz implica um funcionamento global dos mecanismos reguladores do equilíbrio e da atitude e, que os movimentos corporais desempenham um importante papel na melhora dos comandos nervosos e no afinamento das sensações e percepções (TAGLIARI et al., 2008).
Para Zakharov (1992), é necessário que se estimule o jovem aprendiz à prática das habilidades motoras básicas oportunizando a maior gama de vivências motrizes. Isto assegurará, posteriormente, a maximização da aprendizagem específica do desporto praticado. Como ações motoras naturais, as habilidades básicas significam uma função da natureza humana, bastando apenas à estimulação, para que a efetivação do aprendizado dessas habilidades seja conquistada pelas crianças e jovens (MEURER et al., 2008).

A iniciação desportiva acontece quase sempre pela inserção das crianças em escolinhas desportivas específicas, que se desenvolvem na própria escola ou em clubes e projetos sóciodesportivos-culturais. Como cada uma dessas modalidades tem características específicas de suas demandas e, o trabalho específico não contempla o trabalho global em motricidade (VIDAL FILHO et al., 2003). O resultado é um déficit motor, que exclui o pretenso atleta da alta performance. Uma das explicações para isto é que, como o indivíduo não possui o engrama dos movimentos que servem de pré-requisito a outros mais complexos, em algumas situações, o indivíduo não consegue realizar a ação proposta com um mínimo de eficiência diante de tamanha especificidade (como por exemplo, na execução do arremesso em gancho, no basquetebol). $\mathrm{Na}$ verdade, com o aumento da complexidade, a resolução do problema é inviabilizada pelo não domínio dos movimentos básicos da motricidade e, preponderantes ao aprendizado específico em desporto.

Segundo Oliveira et al., (2003), indivíduos considerados exímios desportistas, excelentes em suas performances nas situações de jogo ou competição são normalmente aqueles que se destacam por suas capacidades de entendimento (competência cognitiva) de onde, como e quando utilizar exatamente as técnicas inerentes à performance de um jogo específico, além de, fazer os ajustes e correções necessárias às demandas ambientais e específicas do desporto, por meio de seu feedback intrínseco.

Schmidt e Wrisberg (2001) concordam com este racional e afirmam que, os movimentos de indivíduos habilidosos são caracterizados por um controle mais eficiente e uma coordenação suave das articulações e dos músculos, além da diminuição no gasto de energia, esses indivíduos 
também são capazes da manter a atenção por mais tempo e de identificar os pontos mais relevantes da tarefa. À medida que eles melhoram suas habilidades de hábil-processador, às demandas de atenção para realização dos movimentos diminuem, e assim, tornam-se mais hábeis em identificar e corrigir erros que ocorrem.

A ênfase estaria então, na aquisição de habilidades por meio de resolução de problemas e o fator cognitivo como precedente ao fator motriz (DA SILVA, 2002b).

De fácil inserção nas escolas, o atletismo é considerado desporto de base e contêm, em seu espectro de movimentos, uma série de habilidades consideradas básicas e formativas à alta performance. Tecnicamente descomplicado, varia as ações motoras e pode ser adaptado a qualquer espaço. Após a aprendizagem de uma habilidade no atletismo, o que vai determinar a melhor performance é, principalmente, a produção de força e a resistência de força, todos aspectos concernentes a bioestruturalidade (DA SILVA, 2002b; NISTA-PICCOLO et al., 2004). Já o basquetebol, necessita de espaço adequado, bola, tabela e aro específicos. Desde a sua criação em 1891, na cidade americana de Springfield (Massachusetts), o basquetebol evoluiu e passou por várias transformações em suas regras, técnicas e táticas. Tal evolução fez com que se tornasse um desporto com um alto grau de complexidade técnica de seus movimentos, difícil de ser coordenado em sua plenitude e de alta demanda cognitiva (OKAZAKI et al., 2004). O presente estudo destinou-se a examinar as possíveis diferenças em jovens praticantes de basquetebol e atletismo e se justifica ainda, pela necessidade de se aprofundar num tema ainda pouco explorado, produzindo referenciais sobre as competências bioperacionais necessárias a prática de determinados desportos, bem como, sobre níveis de competências necessários ao bom desempenho desportivo em cada modalidade, observando suas características peculiares.

\section{Método}

\section{Amostra}

Foram selecionados trinta $(\mathrm{N}=30)$ atletas do gênero masculino, com idade variando entre $13 \mathrm{e}$ 16 anos, sendo 15 atletas da equipe de basquetebol do Automóvel Clube Fluminense de Campos e 15 atletas da equipe de atletismo do Clube de Regatas Vasco da Gama, no Rio de
Janeiro. Os sujeitos da amostra tiveram sua participação em caráter voluntário e todos os respectivos responsáveis assinaram um termo de livre consentimento esclarecido, onde constava toda a metodologia empregada. Esta pesquisa seguiu os preceitos e procedimentos éticos de pesquisas feitas com seres humanos, conforme diretrizes da Resolução 196/96, do Conselho Nacional de Saúde sobre pesquisas com seres humanos (BRASIL, 1996) e foi aprovada com número de protocolo 0164/2008 UCB/VREPGPE/COMEP/PROCIMH.

\section{Instrumentação e Procedimentos}

Para mensuração e comparação das variáveis bioperacionais, aqui abordadas (coordenação geral, percepção cinestésica e tempo de reação motriz), foram aplicados três testes, na seguinte ordem: Teste para medir coordenação Burpee, para medir coordenação entre os movimentos de tronco, membros inferiores e superiores; Teste de Salto de Percepção Cinestésica, para medir a percepção cinestésica (FERNANDES FILHO, 2003). Para medir o tempo de reação, utilizou-se o teste de Tempo de Reação Motriz através de um software (gold standard) MAT LAB 5.3. (The math works, Inc.), instalado em um computador portátil (lap top) marca Amazon com um processador Pentium $1.70 \mathrm{GHz}$ e Windows XP. O teste de Tempo de Reação Motriz foi aplicado em uma sala em separado, tanto no Maracanã, com os atletas do atletismo, quanto no Ginásio do CENSA, com os atletas do basquetebol.

Os testes visando à coleta de dados aconteceram no Ginásio do Centro Educacional Nossa Senhora Auxiliadora (CENSA), com os jogadores de basquetebol do Automóvel Clube e, no estádio Célio de Barros (MARACANÃ), com os atletas da equipe de atletismo do Vasco da Gama.

\section{Análise Estatística}

Foi aplicado 0 teste de normalidade Kolmogorov-Smirnov na amostragem utlizada nesta pesquisa. Para responder as questões do estudo, utilizou-se a estatística descritiva com médias, desvios-padrão e, o mínimo e o máximo escore, como estatística de inferência utilizou-se - Teste T Student para amostra independente, por meio do programa SSPS10, com nível de significância de $p \leq 0,05$, ou seja, $95 \%$ de chance de se notar uma afirmativa e/ou negativa no presente estudo. 


\section{Resultados}

Objetivando verificar a normalidade dos dados, foi utilizado o Teste de Kolmogorov-Smirnov (TKS), pois este teste é adequado para verificar se as variáveis estão próximas da normalidade ou da distribuição normal (THOMAS; NELSON, 2002).

Conforme os dados apresentados na TABELA 1, verificou-se que as estimativas de $p$-valor para o TKS, estão acima de 0,05 , logo as variáveis seguem a distribuição normal.

Tabela 1. Avaliação da normalidade dos escores das modalidades esportivas.

\begin{tabular}{lccl}
\hline \multicolumn{1}{c}{ Testes } & Modalidade & Modalidade & Decisão \\
\cline { 2 - 3 } & Basquetebol Sig. & AtletismoSig. & \\
Coordenação & 0,170 & 0,100 & Segue distr. Normal \\
Percepção Cinestésica & 0,090 & 0,200 & Segue distr. Normal \\
Tempo de Reação Motriz & 0,163 & 0,200 & Segue distr. Normal \\
\hline *'́ndice de significância $(\mathrm{p} \leq 0,05)$. & & &
\end{tabular}

Na TABELA 2, TABELA 3 e na TABELA 4 estão os resultados das médias, desvios padrão e dos escores mínimos e máximos dos testes, bem como as comparações intergrupos, através do teste "t" de Student.

Tabela 2. Comparação dos escores entre as modalidades no teste de coordenação.

\begin{tabular}{|c|c|c|c|c|c|}
\hline Teste & $\begin{array}{c}\text { Modalidade } \\
\text { (M } \pm \text { DP) (MÍ / MÁX) }\end{array}$ & $\begin{array}{c}\text { Modalidade } \\
(\mathrm{M} \pm \mathrm{DP})(\mathrm{MI} / \mathrm{MÁX})\end{array}$ & $\mathrm{t}$ & gl & p-valor \\
\hline & Basquetebol & Atletismo & & & \\
\hline $\begin{array}{l}\text { Coordenação (partes } \\
\text { do corpo) }\end{array}$ & $\begin{array}{c}17 \pm 4,58 \\
7 / 25\end{array}$ & $\begin{array}{c}16,13 \pm 3,83 \\
12 / 24\end{array}$ & 479 & 14 & 0.639 \\
\hline
\end{tabular}

$\mathrm{Na}$ análise da TABELA 2 e na ilustração da FIGURA 1, pode-se observar que, a variável coordenação geral não apresentou significância estatística em seus resultados de comparação entre grupos, só que, o grupo de atletas do basquetebol obteve melhor escore na comparação com o grupo de atletas do atletismo.

Figura 1. Média e desvios Padrão dos escores de coordenação entre as modalidades esportivas presentes neste estudo.

\section{TESTE DE COORDENAÇÃO}

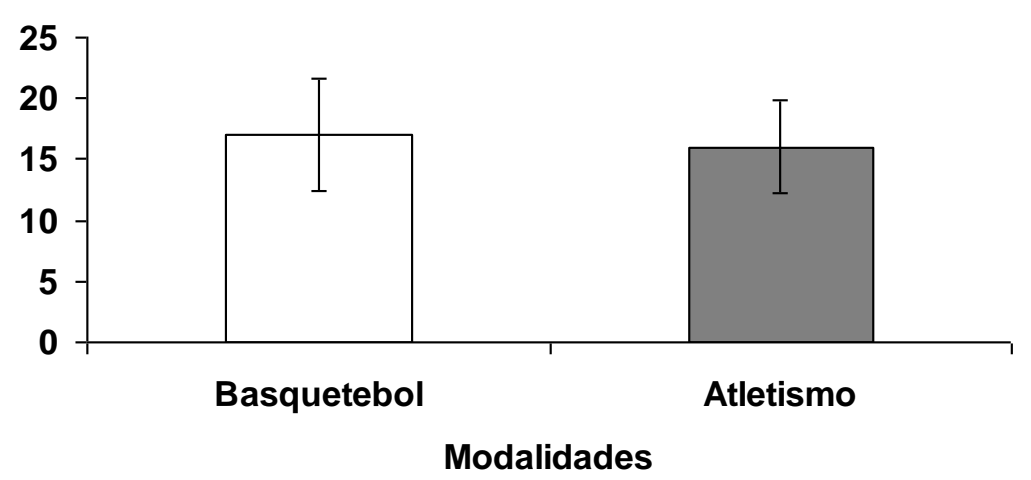

$\mathrm{Na}$ análise inferencial, na TABELA 3, pode-se perceber que não houve diferença significativa entre os grupos de basquetebol e atletismo $(p \leq 0.05)$. 
Tabela 3. Comparação dos escores entre as modalidades no teste de percepção cinestésica.

\begin{tabular}{|c|c|c|c|c|c|}
\hline Teste & $\begin{array}{c}\text { Modalidade } \\
(\mathrm{M} \pm \mathrm{DP})(\mathrm{MI} / \mathrm{MÁX})\end{array}$ & $\begin{array}{c}\text { Modalidade } \\
(\mathrm{M} \pm \mathrm{DP})(\mathrm{MI} / \mathrm{MÁX})\end{array}$ & $\mathrm{t}$ & $\mathrm{gl}$ & p-valor \\
\hline & Basquetebol & Atletismo & & & \\
\hline Percepção & $20,73 \pm 10,77$ & $27,93 \pm 12,16$ & & & \\
\hline Cinestésica $(\mathrm{cm})$ & $4,5 / 44$ & $8 / 45,5$ & -1.558 & 14 & 0,142 \\
\hline
\end{tabular}

Na FIGURA 2, ilustra-se uma tendência de melhor performance do grupo de basquetebol, em relação ao grupo de atletismo, no teste de percepção cinestésica. Tal fato corrobora com estudos desta variável.

Figura 2. Média e desvios padrão dos escores do teste de percepção cinestésica.

\section{TESTE DE PERCEPÇÃO CINESTÉSICA}

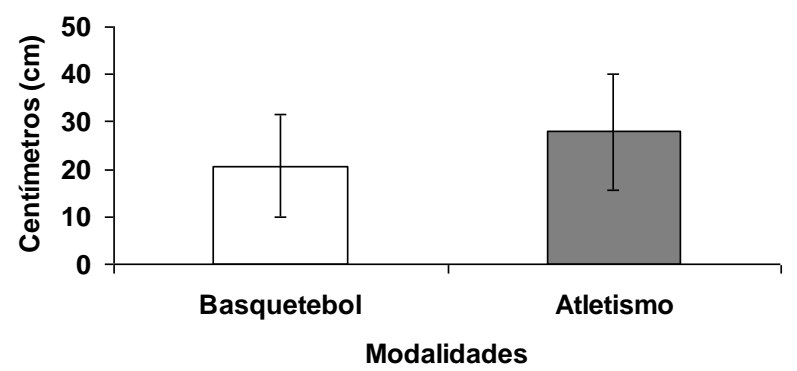

Com relação ao teste de tempo de reação motriz, seu resultado pode ser observado na análise inferencial dos dados, na TABELA 4.

Tabela 4. Comparação dos escores entre as modalidades no teste de tempo de reação motriz.

\begin{tabular}{|c|c|c|c|c|c|}
\hline Teste & $\begin{array}{c}\text { Modalidade } \\
(\mathrm{M} \pm \mathrm{DP})(\mathrm{MI} / \mathrm{MÁX})\end{array}$ & $\begin{array}{c}\text { Modalidade } \\
(\mathrm{M} \pm \mathrm{DP})(\mathrm{MI} / \mathrm{MÁX})\end{array}$ & $\mathrm{t}$ & $\mathrm{gl}$ & $\mathrm{p}$-valor \\
\hline & Basquetebol & Atletismo & & & \\
\hline Tempo de Reação & $378 \pm 38,02$ & $426 \pm 49,08$ & & & \\
\hline Motriz (ms) & $330 / 440$ & $350 / 520$ & $-2,970$ & 14 & $0,010^{*}$ \\
\hline
\end{tabular}

Pode-se afirmar que esta foi à única das três variáveis bioperacionais mensuradas e comparadas que obteve significância estatística, observada na TABELA 4, acima e na FIGURA 3, abaixo.

Figura 3. Média e desvios padrão dos escores do teste de tempo de reação motriz.

TESTE DE TEMPO DE REAÇÃO MOTRIZ

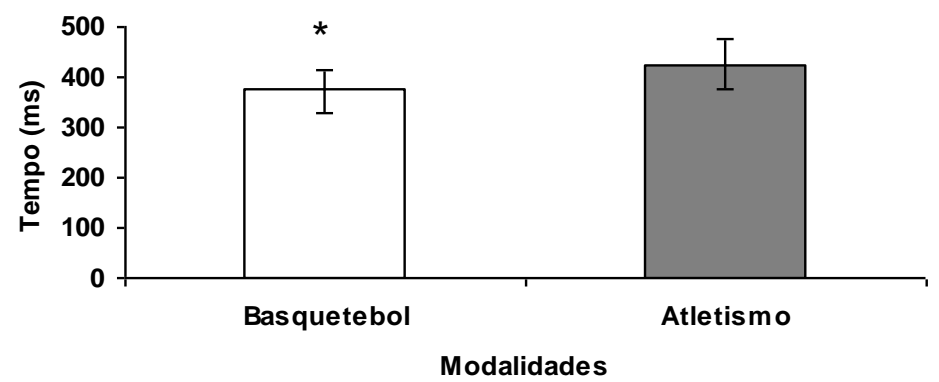

${ }^{*}$ Significativamente menor do que o Atletismo $(p \leq 0,05)$.

\section{Discussão}

A coordenação geral, mensurada por meio do teste de coordenação Burpee (FERNANDES FILHO, 2003), não apresentou significância 
estatística na comparação entre os grupos $(p>0,05)$. No entanto, os atletas do basquetebol, obtiveram melhor escore na comparação com 0 grupo de atletas do atletismo. Não se pode ignorar que esta variável é de suma importância ao aprendizado de qualquer habilidade motriz. Contudo, no contexto dos desportos coletivos, as ações técnico-tácticas individuais representam estratégias motoras singulares, produto da interpretação pessoal que cada desportista faz das diferentes ações do jogo e que dependem de ótima coordenação para que se obtenha êxito na ação motora desejada ou no gesto desportivo pretendido (PEÑAS; GRAÑA, 2001). Pela variedade de movimentos e constantes alterações que se manifestam numa partida de basquetebol (de característica instável e imprevista), pode-se afirmar que, a coordenação geral é primordial para que 0 atleta de basquetebol atinja o "status" de exímio desportista. Não só quando da aprendizagem do gesto motor específico, mas principalmente durante a coordenação de todos os gestos desportivos contidos numa partida de basquetebol.

No atletismo, em especial nas provas de velocidade, a coordenação geral também é de suma importância. No entanto, como este é um desporto com movimentos cíclicos, sem a presença do inusitado e de pouca demanda cognitiva, esta competência se evidenciará, principalmente, na aprendizagem do gesto motor. Após o engrama da habilidade pretendida, a memória de procedimentos se encarregará de dar o comando aos músculos para a realização de tal habilidade, sem necessidade de processamento em nível cortical. Ou seja, a demanda por coordenação é maior quando da aprendizagem, ficando a produção de força como principal característica dos velocistas do atletismo, principalmente em categoria adulta. $\mathrm{O}$ que determinará a melhor performance é a produção de força (variável bioestrutural).

A segunda variável verificada neste estudo foi à percepção cinestésica. Na análise dos escores do teste de percepção cinestésica, também não houve diferenças significativas entre os atletas dos dois grupos $(p>0,05)$, mas os escores dos atletas de basquetebol foram melhores, em relação aos velocistas do atletismo. Embora não se tenha observado significância estatística, estudiosos no assunto afirmam que esta competência é de suma importância ao ótimo desempenho em desportos de contato corporal, principalmente, em desportos como o basquete e o futebol, em que a bola é presente $\underline{\text { SAAD, 2006; }}$ PINTO et al., 2001; GRECO, 1998; NISTA-
PICCOLO et al., 2004; SANCHOTENE et al., 2004). Corroborando com este racional, Brandl (2005), ao considerar a definição de Gardner (1995) sobre a inteligência corporal cinestésica e associá-la ao basquetebol, destacou esta modalidade como rica em diversidade de ações técnicas e resoluções, com demonstração de diferentes manifestações de inteligência corporalcinestésica. Brandl (2005) segue relatando que, os jogadores são capazes de manipular objetos com refinamento demonstrando uma inteligência corporal, em usar o próprio corpo para jogar. Tagliari et al. (2008), corroborando com essa afirmativa, acrescentam que o desporto coletivo tem caráter dinâmico e exige diferentes habilidades e competências dos seus praticantes e que, as habilidades percepto-motrizes são prérequisito para a aprendizagem das habilidades motoras específicas. Essas afirmativas são confirmadas por resultados obtidos em estudos feitos com escolares e jogadores de basquete, onde essa competência foi considerada determinante para a alta performance do praticante dessa modalidade e para o bom desempenho na iniciação desportiva (NISTAPICCOLO et al., 2004; PEÑAS; GRAÑAS, 2001).

A terceira e última variável mensurada e comparada neste estudo foi o tempo de reação motriz. Pela análise dos resultados no teste de tempo de reação motriz, pode-se afirmar que esta foi à única das variáveis que obteve significância estatística $(p \leq 0,05)$. Desta forma, ficou evidente a superioridade do grupo de atletas de basquetebol na comparação com o grupo de velocistas do atletismo.

A mensuração do tempo entre o aparecimento de um estímulo e o momento de iniciação de uma resposta correspondente, é normalmente denominado, tempo de reação ou resposta e, reflete-se da pendência de orquestração neural entre sensores orgânicos, tradutores e estruturadores centrais, além de um núcleo de comando que deflagra o início da resposta para uma ação. Estes representam, em outros termos, os mecanismos de processamento de estímulo e reposta, tradicionalmente estudados sob forma de três estágios de processamento mental denominados, percepção, seleção e programação de respostas (DA SILVA et al., 2008).

O tempo de reação pode ser definido ainda, como o intervalo de tempo que decorre entre a apresentação de um estímulo não antecipado até o início da resposta do indivíduo (MAGILL,1998), é o tempo que um indivíduo leva para tomar decisões e iniciar ações, portanto, representa 
uma medida do indicador da velocidade de processamento de informação, sendo uma medida importante da aprendizagem e da performance humana (ENOKA, 1995), além de ser uma das medidas de desempenho muito utilizadas, para indicar o resultado de habilidades motoras (SCHMIDT; WRISBERG, 2001; SILVA et al., 2007). Na prática esportiva, bem como em situações especiais da vida animal, o tempo de reação pode ser decisivo e definir a qualidade da ação e do comportamento do indivíduo respondente (DA SILVA et al., 2008; SILVA et al., 2007).

Da Silva et al. (2008), afirmam, a partir da perspectiva neurofisiológica associada ao treinamento do tempo de reação, que o mesmo se compõe de duas partes neurais distintas, mas inclusivas. Ou seja, uma relativa à condução nervosa ou não-treinável, enquanto que a outra, ao processamento central do evento. Estes mesmos autores (2008) categorizam a primeira parte do tempo de reação como uma função de natureza bioestrutural e a segunda parte como um fator orgânico de correspondência bioperacional que pode ser melhorado através de treinamento específico. Considerando-se que a unidade bioestrutural não se modifica em função de um treinamento, quais seriam as mudanças, dele decorrentes, em termos da estruturação bioperacional, implícita em uma resposta para um estímulo complexo? Sujeitos mais hábeis do ponto de vista cognitivo, considerados experts desportistas, realizam tarefas de uma forma mais rápida e eficiente (DA SILVA, 2002a; RIBEIRO; ALMEIDA, 2005). Tal superioridade é explicada pela singularidade da natureza do especialista motor, em particular em modalidades com alta demanda de tomada de decisão, onde estaria apoiada em uma base de conhecimento superior (DANTAS; MANOEL, 2008). Desta forma, as correlações ganham ainda maior relevância estatística quando os estudos envolvem os tempos de reação em tarefas mais complexas (NECKA, 1992).

Para Zakharov (1992), as capacidades de velocidade estão manifestadas na possibilidade de o atleta, no menor tempo possível, executar ações motoras, sendo que um dos componentes principais da capacidade de velocidade é a rapidez, que se manifesta em duas formas principais: rapidez de ação motora e rapidez de movimento. No entanto, para Chagas et al. (2005), o tempo de reação motriz, não pode ser associado ao desempenho em habilidades, que envolvam movimentos rápidos. Apesar da capacidade de velocidade de movimento ser fundamental dentro das exigências motrizes, nos desportos coletivos como futsal e basquetebol, por exemplo, (desportos coletivos e de contato corporal), ele não reflete uma característica de potencial velocidade relacionada às demandas específicas de cada desporto.

O tempo de reação é um fator que pode ser decisivo para melhora do desempenho tanto em esportes de combate como o taekwon-do, como também em esportes coletivos, como o futebol (DA SILVA et al., 2008) e, sem dúvida, em outros (RODRIGUES; RODRIGUES, 1984; DA SILVA et al., 2008).

O Basquetebol é um desporto que exige de seus praticantes altos níveis de competência técnico-tática, possui altíssima e constante demanda cognitiva, sendo ainda absolutamente controlado por tempo e com o andamento do jogo totalmente sob supervisão de árbitros e fiscais. Ao considerar que em uma partida de basquetebol, o atleta tem 24 segundos de tempo total de posse de bola; oito segundos para cruzar com a bola da defesa pro ataque; três segundos de permanência no garrafão de ataque; cinco segundos na retenção de bola e, para cobrar uma infração, mais cinco segundos. Já no atletismo esta competência é mais requisitada durante a saída do bloco de partida, a partir da velocidade de condução do estímulo auditivo.

Nesse sentido, desenvolver em um atleta a habilidade de perceber, interpretar e agir corretamente para um estímulo qualquer, em um menor tempo possível, pode representar um diferencial na estratégia de ação, não só destas modalidades esportivas citadas no estudo, como de qualquer outra modalidade de expressão competitiva. Não se pode esquecer que, de forma geral, a velocidade de processamento mental é fundamental, inclusive, para a vida comum social do homem. Segundo resultados em estudos sobre esse tema (RODRIGUES; RODRIGUES, 1984; DA SILVA et al., 2008), a forma de se treinar esta competência, pode ser mais rentável à medida que aquele processamento receba uma estimulação adicional. Partindo-se do princípio que desportistas que praticam modalidades abertas, em função da natureza destas modalidades e do treinamento para o desempenho das mesmas, conduzem, para 0 cérebro, um tipo de estimulação que indivíduos não praticantes de esportes não 0 fazem. Andrade et al. (2007), em estudo recente, relatam que apesar da velocidade de reação de um individuo ser predisposta geneticamente, é possível melhorá-la através do treinamento e, essa melhora pode atingir $15 \%$. 
Assim, Fontani et al. (2006) identificaram em atletas de voleibol experientes uma alta atenção e estabilidade referentes aos escores de tarefas de reações complexas, em relação aos atletas não experientes.

Desta forma, planificações de treinamentos táticos são essenciais para o desenvolvimento do tempo de reação dos atletas, pois são introduzidas atividades cognitivas que envolvem saberes múltiplos e variadas operações mentais, que por si só, venham a estimular as condutas originais. Essa abertura impede que 0 atleta antecipe as conseqüências de suas escolhas com uma elevada margem de erro, o que estimula o mesmo a admitir a necessidade de uma conduta reflexiva acerca de suas atividades cognitivas, afastando-o de um comportamento automatizado e reprodutivo (RIBEIRO; ALMEIDA, 2005). Observa-se que estas condutas se relacionam com a atividade do córtex intraparietal lateral, visto que estão ligadas, com a precisão das respostas e velocidade de percepção (ROITMAN; SHADLEN, 2002).

Estes achados estão de acordo com dados clínico-anatômicos e de imagem funcional, na regulação da flexibilidade cognitiva dos mecanismos de intenção e execução (MOLL et al., 2002).

\section{Conclusão}

Os resultados encontrados neste estudo apontaram o grupo de atletas de basquetebol como melhor grupo, quando da comparação com o grupo de velocistas do atletismo. Apesar da variável tempo de reação motriz ter sido a única variável que obteve significância na estatística inferencial, pode-se afirmar, baseando-se na estatística descritiva, que os atletas de basquetebol foram melhores que os velocistas do atletismo, também na mensuração das outras variáveis bioperacionais abordadas neste estudo. Esse resultado corrobora para o pressuposto teórico deste estudo que tinha como principal hipótese, um melhor escore do grupo de basquetebol. Tal resultado pode ser atribuído às características peculiares do basquetebol que, é intensamente dinâmico, aberto em termos de feedback e cuja competência de jogo depende de uma multiplicidade de variações mentais no menor tempo possível. Esses resultados encontrados também contribuem para credenciar o basquetebol como atividade desportiva de alta demanda cognitiva.
Um fator a ser considerado nesta análise, diz respeito a resultados encontrados por Stoflles et al. (2007), que em estudo feito com um pequeno grupo de jovens velocistas dos $100 \mathrm{~m}$ rasos, encontraram resultados que sugeriram que, por serem ainda jovens, os atletas avaliados nesse tipo de estudo podem não traduzir em seus resultados, a realidade do alto rendimento. Uma sugestão para futuros estudos sobre o tema seria uma nova coleta de dados com a mensuração e comparação dos escores de atletas profissionais destes mesmos desportos e nestas mesmas variáveis.

\section{Referências}

ANDRADE, A.; BELMONTE, A.P..; VIANA M.S. Tempo de reação, flexibilidade e velocidade acíclica de membros inferiores de atletas de tae kwon do. Revista Digital - Buenos Aires Ano 11 - № 96 - Maio de 2006. Disponível em: http://www.efdeportes.com/ Acesso em 23 ago. 2007

BRANDL, C.E.H. A estimulação da inteligência corporal cinestésica no contexto da Educação Física Escolar. 2005. Tese (Doutorado em Educação Física)-Faculdade de Educação Física da UNICAMP, Campinas, 2005.

BRASIL, Conselho Nacional de Saúde, Resolução 196/96. Lei № 78080 de 19 de setembro de 1990 e Lei № 8.142 , de 28 de dezembro de 1990. CNS, 10 de outubro de 1996.

CHAGAS, M.H.; LEITE, C.M.F.; UGRINOWTSCH, H.; BENDA, R.N.; MENZEL, HJ.; SOUZA, P.R.C.; MOREIRA, E.A. Associação entre tempo de reação e de movimento em jogadores de futsal.

Revista Brasileira de Educação Física e

Esporte, São Paulo, v.19, n.4, p.269-75, out./dez, 2005. Disponível em:

http://www.usp.br/eef/rbefe/v19n42005/sumariov1 9n4.html Acesso em: 15 ago. 2008

DANTAS, L.E.P.B.T.; MANOEL, E.J. Conhecimento e desempenho do especialista motor. Revista da Educação Física/UEM, Maringá, v. 19, n. 3, p. 333-341, 3. trim, 2008. Disponível em: http://www.periodicos.uem.br/ojs/index.php/RevE ducFis Acesso em: 27 dez. 2008

DA SILVA, V. F.; POLY, M.W.O.; RIBEIRO JÚNIOR, S.M.S.; CALOMENI, M.R.; PINTO, M.V.M.; SILVA, A.L.S. Efeito agudo da estimulação cerebral, através de luz e som, no tempo de reação motora de jovens atletas.

Revista Digital - Buenos Aires - Ano 13 - $\mathrm{N}^{\circ}$ 120, Maio, 2008. Disponível em: 
http://www.efdeportes.com/ Acesso em: 13 ago. 2008

DA SILVA, V. F. Os compêndios biooperacional e bio-estrutural como fatores interativos da aprendizagem neural. In: Fernanda Barroso Beltrão; Heron Beresford; Nilza M Macário. (Org.). Produção em Ciência da Motricidade Humana. 2 ed. Rio de Janeiro: Shape, 2002b, v. 2, p. 71-79.

DA SILVA, V. F. Treinamento neurogênico biooperacional: Uma perspectiva da aprendizagem motora. In: Rogério Vilela de Abreu Pereira; Raimundo Nonato de Azevedo; Mauro Cesar Gurgel de Alencar Carvalho. (Org.). Força: Aspectos básicos do treinamento. 1 ed. Rio de Janeiro: AZ, 2002a, v. 01, p. 93-126.

ENOKA, R.M. Mechanisms of muscle fatigue central factors and tasks dependency. Journal of Electromyography and Kinesiology, Volume 5, Number 3, pp. 141-149(9), 1995. Disponível em: http://journalseek.net/cgi-

bin/journalseek/journalsearch.cgi?field=issn\&quer $\mathrm{y}=1050-6411$ Acesso em: 22 ago. 2007

FERNANDES FILHO, J. A prática da avaliação física; testes, medidas e avaliação física em escolares, atletas e academias de ginástica. $2^{a}$. Ed., revisada e atualizada. Rio de Janeiro: Shape editora, 2003.

FONTANI, G.; LODI, L.; FELICI A.; MIGLIORINI, S. CORRADESCHI, F. Attentional in athletes of high and low experience engaged in different open skill sports. Perceptual and Motor Skills, 102 (3), pags 791-805, 2006. Disponível em: http://ammons.ammonsscientific.com/php/toc.php Acesso em: 22 set. 2007

GRECO, P. J. Iniciação esportiva universal: metodologia da iniciação esportiva na escola e no clube. Belo Horizonte, Editora Universitária, UFGM. 1998.

\section{MAGILL, R. A. Aprendizagem motora:}

Conceitos e aplicações. 5 ed. São Paulo. Edgar Bluche, 1998.

MEURER, S. T.; SCHAEFER, R. J.; MIOTTI, I. M. L. Atletismo na escola: uma possibilidade de ensino. Revista Digital - Buenos Aires - Ano 13 - No 120, Maio, 2008. Disponível em: http://www.efdeportes.com/ Acesso em: 12 jun. 2008

MOLL, J.; OLIVEIRA-SOUZA, R.; MOLL, F.T.; BRAMATI, I.E.; ANDREIUOLO, P.A. The cerebral correlates of set-shifting: an $\mathrm{fMRI}$ study of the trail making test. Arquivo de Neuropsiquiatria, 60(4):900-905, 2002.
http://dx.doi.org/10.1590/S0004282X2002000600002

NECKA, E. Cognitive analysis of intelligence: The significance of working memory processes.

Personality and Individual Differences, 13, pags 1031-1046, 1992. Disponível em:

http://www.elsevier.com/wps/find/journaldescriptio n.cws home/603/description\#description Acesso em: 24 set. 2006

NISTA-PICCOLO, V. L.; PRODÓCIMO, E.; SOUZA, M. T.; BRANDL, C. E. H.;

ZYLBERBERG, T. P.; FARIAS L. Manifestações da inteligência corporal cinestésica em situação de jogo na educação física escolar. Revista Brasileira de Ciência e Movimento, Brasília v. 12 n. 4 p. 25-31 dez, 2004. Disponível em: http://biblioteca.cev.org.br/br/biblioteca/refelnet/re vista.asp?cod=74 Acesso em: 12 nov. 2008

OLIVEIRA, F..; BELTRÃO, F.; SILVA, V. F. Metacognição e hemisfericidade em jovens atletas: Direcionamento para uma pedagogia de ensino desportivo. Revista Paulista de Educação Física, São Paulo, 17(1); 5-15 jan/jun, 2003. Disponível em: http://www.usp.br/eef/rpef/ Acesso em: 14 ago. 2007

OKAZAKI, V.H.A., RODACKI, A.L.F., SARRAF, T.A., DEZAN, V.H., OKAZAKI, F.H.A. Diagnóstico da especificidade técnica dos jogadores de basquetebol. Revista Brasileira de Ciência e Movimento. Brasília v. 12 n. 4 p. 19-24 dezembro 2004. Disponível em:

http://biblioteca.cev.org.br/br/biblioteca/refelnet/re vista.asp?cod=74Acesso em: 12 nov. 2008

PEÑAS, C.L.; GRAÑAS, P.L. Las capacidades coordinativas en los juegos deportivos colectivos. el balonmano. Revista Digital - Buenos Aires Ano 6 - N 30 Fevereiro, 2001. Disponível em: http://www.efdeportes.com/ Acesso em: 22 ago. 2005

PINTO D.; GONÇALVES I.; GRAÇA A. Análise da carga de treino e competição em basquetebol no escalão de iniciados. In: I CONGRESO IBÉRICO DE BALONCESTO, Viernes, 2001. Anais... Faculdade de Ciências do Desporto e Educação Física. Universidade do Porto, 2001.

RIBEIRO, R.B.; ALMEIDA, L.S. Tempos de reação e inteligência: a robustez dos dados face à fragilidade da sua interpretação. Avaliação Psicológica. v. 4 n.2 nov, Porto Alegre, 2005. http://dx.doi.org/S1677-04712005000200002

RODRIGUES, S. C. P.; RODRIGUES, M. I. K. Estudos da correlação entre tempo de reação e tempo de movimento no karatê. Revista Kinesis. n. Especial, p. 107, 1984. Disponível em: 
http://www.ufsm.br/cefd/kinesis/ficha\%20kinesis.h tm Acesso em: 12 ago. 2006

ROITMAN, J. D.; SHADLEN, M. Response of neurons in the lateral intraparietal area during a combined visual discrimination reaction time task. The Journal of Neuroscience, November 1 , 22(21):9475-9489, 2002. Disponível em: http://www.jneurosci.org/ Acesso em: 11 ago. 2006

SAAD, M.A. Iniciação nos jogos esportivos coletivos. Revista Digital - Buenos Aires. Ano 11. №. 95, Abril, 2006. Disponível em: http://www.efdeportes.com/ Acesso em: 12 jun. 2005

SANCHOTENE, L. E.; PAIM, M.C.C.; PEREIRA, E.F.; VILLIS, J.C.; GRAUP, S.; HAUTRIVE, H.G.; BRANDÃO, G.G. Inteligência corporal-cinestésica em alunos de escolas de futsal. Revista Digital Buenos Aires - Ano 10 - № 78, Novembro, 2004. Disponível em: http://www.efdeportes.com/ Acesso em: 22 nov. 2005

SCHMIDT, R. A.; WRISBERG, C. A. Aprendizagem e performance motora: uma abordagem da aprendizagem baseada no problema. 2. ed. Porto Alegre: Artmed, 2001.

SILVA, M. A. S.; LIMA, E. V.; CARVALHO, F.A.S. A relevância do tempo de reação em modalidades esportivas. In: XI ENCONTRO LATINO AMERICANO DE INICIAÇÃO CIENTÍFICA E VII ENCONTRO LATINO AMERICANO DE PÓS-GRADUAÇÃO, Urbanova, 2007. Anais... UNIVAP Urbanova, 2007 p. 16281631. Disponível em www.inicepg.univap.br/INIC 07/trabalhos/saude/e pg/EPG00034 04C.pdf Acesso em: 22 ago. 2008

STOFFELS, F.; KOBER, R.S.; PUPO, J.D. Análise de variáveis cinemáticas da corrida de jovens velocistas. Revista Portuguesa de Ciências do Desporto, jan., vol.7, no. 1, p.59-67, 2007. Disponível em: http://www.fade.up.pt/rpcd/entrada.html Acesso em: 22 nov. 2008

TAGLIARI, C. C.; CHODUR, A.; REZENDE, G.; LADEWIG, I. Comparativo da habilidade motora em diferentes idades na modalidade futebol.

Revista Digital - Buenos Aires - Año 13 - № 121 - Junio de 2008. Disponível em: http://www.efdeportes.com/ Acesso em: 13 ago. 2008

THOMAS, J.R.; NELSON, J.K. Métodos de Pesquisa em Atividade Física. $3^{\text {a }}$ Edição. Porto Alegre. Artmed, 2002.

VIDAL FILHO, J. C. B.; HERRERA, J. B.; BOTTARO, M. As Respostas fisiológicas em pré- adolescentes durante o Jogo de basquetebol. Revista Brasileira de Ciência e Movimento, Brasília v. 11 n. 3 p. 21-26 jul./set, 2003.

Disponível em:

http://www.ucb.br/mestradoef/RBCM/rbcm edicoe s.htm Acesso em: 12 jan. 2008

\section{ZAKHAROV, A. A Ciência do Treinamento}

Desportivo. Adaptação Científica Antonio Carlos Gomes. Grupo Palestra Sport. Rio de Janeiro, 1992.

Esse artigo foi apresentado em Sessão Temática no VI Congresso Internacional de Educação Física e Motricidade Humana e XII Simpósio Paulista de Educação Física, realizado pelo Departamento de Educação Física do IB/UNESP Rio Claro, SP de 30/4 a 03/5 de 2009.

\section{Endereço:}

Nilo Terra Arêas Neto

Av. Deputado Alair Ferreira, 201. Turf Club

Campos RJ Brasil

28024-600

Telefone: (22) 8132.2853

e-mail: terra.nilo@gmail.com

Recebido em: 10 de fevereiro de 2009.

Aceito em: 03 de abril de 2009.

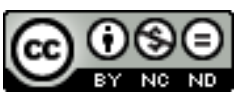

Motriz. Revista de Educação Física. UNESP, Rio Claro, SP, Brasil - elSSN: 1980-6574 - está licenciada sob Licença Creative Commons 